\title{
"Quero ser senhor do meu fucinho": a face agrária da Revolução Federalista nas matas do Rio Grande do Sul (1893-1895)
}

"I want to be the lord of my muzzle": agrarian face of the Federalist Revolution in the forests of Rio Grande do Sul (1893-1895)

"Quiero ser dueño de mi hocico":Ia faceta agraria de la Revolución Federalista en las matas de Rio Grande do Sul (1893-1895)

Marcio Antônio Both da Silva*

\section{Resumo}

Neste artigo, a partir da análise de fontes que foram produzidas por pessoas que tiveram participação na Revolução Federalista (1893-1895), seja como soldados rasos ou como lideranças militares e políticas, da contraposição desses documentos com a bibliografia que tratou de estudar o evento, busco discutir os diferentes sentidos que a Revolução Federalista adotou na região de matas do Rio Grande do Sul - municípios de Cruz Alta, Palmeira das Missões, Passo Fundo e Santo Ângelo. Interessa mostrar o quanto os variados significados expressavam a condição social e as situações então experimentadas pelas populações rurais que viviam na região.

Palavras-chave: Monarquia. Povoamento. República. Revolução.
Doutor em História pela Universidade Federal
Fluminense. Professor do Curso de Graduação e do
Programa de Pós-Graduação em História da Uni-
versidade Estadual do Oeste do Paraná. E-mail:
marcioboth@gmail.com

Recebido em 02/03/2017 - Aprovado em 20/04/2017 http://dx.doi.org/10.5335/hdtv.17n.2.7493 


\section{Introducãa}

A passagem da Monarquia à República, embora já tenha sido alvo de diferentes abordagens, realizadas a partir de variadas perspectivas teóricas e históricas, é um assunto ainda não encerrado e, portanto, guarda uma série de lacunas que precisam ser preenchidas. Um dos temas diz respeito à importância e ao papel que a Revolução Federalista de 1893 teve na configuração do regime republicano brasileiro. Mesmo que esse evento, em termos práticos, tenha se restringido aos estados do Sul do Brasil (Rio Grande do Sul, Santa Catarina e Paraná), não deixou de ter influência em contextos sociais e políticos mais amplos.

Neste artigo, de modo diferente do que tradicionalmente foi produzido sobre a Revolução Federalista, buscarei direcionar a atenção para sua conotação agrário-camponesa. $\mathrm{O}$ olhar e as análises estarão voltados a compreender os seus significados na região de matas do Rio Grande do Sul. Interessa, mais diretamente, a presença, a participação e o impacto do conflito entre as populações rurais que viviam na região: grupos de lavradores pobres constituídos basicamente por colonos imigrantes e seus descendentes, indígenas, populações remanescentes da escravidão, pequenos posseiros e aqueles grupos tradicionalmente conhecidos como "caboclos". ${ }^{1}$

Por "região de matas" entende-se, neste texto, o território constituído pelos municípios de Cruz Alta, Palmeira das Missões, Passo Fundo e Santo Ângelo, municipalidades localizadas na parte norte do Rio Grande do Sul e que constituíam um dos últimos espaços de fronteira agrária do estado. Local para onde estava sendo direcionado o movimento colonizador levado a cabo principalmente por imigrantes europeus e seus descendentes e que era administrado pelo Estado e por empresas particulares de colonização.

Uma das principais características desse processo foi o modo conflituoso como aconteceu, visto que expressou o avanço da sociedade nacional, especialmente via projetos de colonização com imigrantes, em direção às áreas de fronteira agrária. Contudo, esse avanço, diferentemente do que se busca fazer crer, não aconteceu em espaços vazios, mas em locais que historicamente eram ocupados por populações que tinham um modo de vida próprio e que foram alvo de expropriações e violências diversas. Assim, o objetivo deste estudo é tratar do envolvimento desses grupos sociais na Revolução Federalista, destacando que os seus motivos não eram os mesmos que os das elites regionais. Dessa forma, proponho que tal participação era resposta e estava articulada à complexa situação vivida pelos habitantes da região.

De uma maneira geral, a mudança de quadros diretivos estaduais que acompanhou a passagem da Monarquia à República não aconteceu de forma pacífica, mas envolveu resistência dos grupos que estavam sendo substituídos contra os novos "donos do poder". O Rio Grande do Sul, da virada do século XIX para o XX, passou por um processo de transferência do predomínio político estadual de uma elite estancieira vinculada ao Partido Liberal, cuja chefia estava nas mãos de Gaspar Silveira Martins, para um novo grupo político. Grupo formado por pessoas menos dependentes da produ- 
ção bovina (charque e couro - produtos que dominaram a economia sul-rio-grandense no período imperial e nas primeiras décadas do século $X X)$ e que estava mais diretamente vinculado às zonas agrícolas e industriais que passaram a se desenvolver nos finais do século XIX e se situavam na parte norte do estado, na capital e na região metropolitana de Porto Alegre (PICCOLO, 1983, p. 40).

Esse novo grupo era politicamente chefiado por Júlio de Castilhos e aglutinava-se em torno do Partido Republicano Rio-Grandense (PRR), fundado na década de 1880. Em termos estruturais, tinha poder econômico proporcionalmente menor, mas que rivalizava com os representantes da antiga elite imperial. Contudo, politicamente, tinham vínculos maiores e mais sólidos com a recém-implantada República. Situação que lhes garantia uma maior inserção e margens de manobra dentro do conjunto de mudanças, principalmente políticas, que aconteciam não só no Rio Grande do Sul, mas no país como um todo (PESAVENTO, 1983; FAY, 1993). Dois grupos sólidos economicamente, sendo perceptível que a balança do poder político passava a pender para o lado das classes sociais aglutinadas em torno de Júlio de Castilhos e do PRR. Vale lembrar que, no Rio Grande do Sul, foi deles o protagonismo no processo que levou à derrubada da Monarquia e à implantação da República.

Esse conjunto de fatores dá uma configuração especial à Revolução Federalista na região. $O$ historiador Sérgio da Costa Franco, por exemplo, escreve que, diferentemente da região da campanha e da fronteira onde a Federalista foi uma sedição de elites, na região de matas, ela
[...] ganhou as tintas de uma "jacquerie" desordenada revolta camponesa em que o saque e a vingança tinham prevalência sobre qualquer objetivo político (FRANCO, 1989, p. 10).

Este modo de interpretar o acontecimento não está de todo errado, entretanto, o fato de ser uma "revolta camponesa" não pode necessariamente levar à conclusão de que, na região, a Federalista não teve objetivos políticos. Necessário se faz ampliar a compreensão do que é a política ou do que seja uma ação política. Assim, há que se considerar que:

[...] é apenas folclore dos especialistas militares dizer que "o único desejo dos camponeses é que os deixem em paz". Não é verdade. Quando não têm pão, querem pão; quando não têm terra, querem terra; quando são enganados pelos funcionários de uma remota capital, querem se ver livres deles. Mas, acima de tudo, querem gozar de seus direitos como seres humanos e, quando dominados por estrangeiros, querem se livrar deles (HOBSBAWM, 1982, p. 167-168).

Outrossim, na fronteira e na campanha, a Federalista não foi apenas uma "sedição de elites". Em sua pesquisa sobre o problema, John Chasteen (2003) demonstra que os motivos que impeliam as elites dessas regiões não eram os mesmos que levaram peões e agregados a participar do conflito. Estudar a Revolução Federalista, no caso específico da região de matas do Rio Grande do Sul, portanto, passa pelo problema de pensar a questão da propriedade da terra, pelo modo como se desenvolveu a colonização com imigrantes, pela existência de diferentes concepções a respeito da propriedade e do uso da terra, pela questão da gênese so- 
cial dos grupos direta ou indiretamente envolvidos no processo de povoamento e pelo modo como a revolução chegava às pessoas que viviam naquele espaço.

Desde este ponto de vista, Jorge Luiz Mattar Villela (2004), ao estudar aspectos vinculados à violência e à política no sertão de Pernambuco durante a Primeira República, avançou muito no sentido de romper com a ideia de que as classes populares, devido à sua pobreza e à falta de instrução, são agentes históricos passivos e facilmente iludidos. Villela destaca que, naquele contexto, as pessoas poderiam, dependendo do problema no qual estavam envolvidas, entrar em diferentes disputas, muitas das quais tinham pouca ou nenhuma relação direta com seus problemas próprios, a partir de escolhas feitas com base em suas experiências cotidianas. Em outras palavras, o fato de que tais grupos, em suas ações, vinculações e mobilizações, não tinham como horizonte de perspectiva a tomada do Estado não deve repercutir na conclusão de que sejam apolíticos.

Todavia, a historiadora Cláudia Wasserman, ao tratar da Revolução Federalista e da Revolução de 1923, escreve que:

[...] essas guerras foram causadas por cisões ocorridas no seio das classes dominantes e o envolvimento das tropas, peões, populares esteve ligado apenas às convocações feitas pelas elites (2004, p. 273).

Segundo a autora, as demandas populares nunca estiveram presentes nos dois conflitos. Acredito que não existam grandes dúvidas de que um dos principais aspectos a caracterizar a Federalista no Rio Grande do Sul tenha sido as cisões dentro das clas- ses dominantes e que oficialmente ela não atendia a demandas populares. Todavia, explicar a participação das classes populares apenas pelas "convocações feitas pela elite" pouco ajuda no entendimento completo da participação e de seus motivos.

No caso específico da região de matas, também há uma historiografia que foi produzida buscando entender os significados da Revolução Federalista naquele contexto. Loiva Otero Félix (1996), por exemplo, ao tratar do tema, postula que na região é possível localizar dois grupos mobilizados e envolvidos na contenda. Para descrevê-los, Felix divide-os em duas categorias classificativas: o "poder do mato" e o "poder do campo". O primeiro era formado por ervateiros, lavoureiros e chacareiros, os quais se identificam com as forças de oposição política. Já o segundo era composto por "estancieiros identificados com as forças do situacionismo/castilhismo" (FELIX, 1996, p. 95-96).

À primeira vista, parece que as classes populares (formadas por indígenas, afrodescendentes, pequenos posseiros, jornaleiros, peões, agregados, etc.), que histórica e tradicionalmente habitavam as regiões dominadas pela floresta, aderiram em sua maioria às forças federalistas. Entretanto, isso não pode ser tomado como um fato determinante, uma camisa de força, a definir a adesão e a inserção política de tais grupos. Como veremos adiante, outros fatores mais estavam envolvidos. De qualquer modo, há que se reconhecer que a situação em que estavam submersos os habitantes tradicionais da região florestal - em sua maioria lavradores pobres, que não tinham o domínio jurídico das terras que ocupavam - fazia-os ver o 
governo, suas forças e seus apoiadores como inimigos a serem combatidos. ${ }^{2}$

Cabia ao governo a administração do processo de colonização e de discriminação do domínio público e privado da terra, fatores que impactavam diretamente na vida dessas pessoas e eram responsáveis pela sua expulsão dos espaços que historicamente ocupavam, influenciando, assim, diretamente no sentido de definir suas escolhas. Esses fatores também ajudam a compreender a força e a capacidade de mobilização dos federalistas na região (ARDENGHI, 2003), mas não devem obscurecer o fato de que muitas das pessoas que lá viviam, não só os estancieiros (poder do campo), inscreveram-se e lutaram ao lado das tropas legalistas.

Em outros termos, dinâmicas e profundamente complexas são as razões pelas quais os integrantes das camadas populares entram em determinadas disputas, as quais, muitas vezes, não são necessariamente promovidas por questões particulares. Elas só podem ser mais bem compreendidas quando analisadas a partir do ponto de vista daqueles que tomam a decisão e do contexto socio-histórico vivido e experimentado. Outrossim, há que se considerar que agir socialmente é agir a partir de um lugar ocupado no mundo social e da participação em uma complexa gama de relações sociais interdependentes. Dessa forma, em sociedade, toda ação, por mais individual que pareça ser, está imbricada a uma rede sem fim de outras inter-relações (ELIAS, 1994).

Além disso, algumas ações sociais podem adotar o sentido da estratégia, a qual é constituída com base no cotidiano, a partir das experiências cognitivas, das posições ocupadas e da história vivenciada por aqueles que agem. Embora, à primeira vista, algumas dessas posições e ações pareçam ser contraditórias, é possível encontrar coerência nelas, especialmente quando se tem em vista que são realizadas levando em consideração o espaço de possibilidades que a condição e o lugar ocupado no mundo social proporcionam a quem age. Vale lembrar, ainda, que esse espaço de possibilidades pode ser ampliado ou diminuído, dependendo do poder, dos capitais e do prestígio mobilizados pelos indivíduos ou grupos envolvidos na relação (BOURDIEU, 1982).

\section{A polissemia de sentidos da Revolução Federalista nas matas do Rio Grande do Sul}

Para dar conta dos objetivos propostos, utilizarei como fonte documentos elaborados durante o período, basicamente diários de campanha, relatórios governamentais e descrições memorialísticas. Fontes que, pelo modo como foram produzidas e por quem as produziu, são carregadas de parcialidades, especialmente quando se quer discutir a presença e a participação de pessoas e grupos sociais que não participavam do mesmo mundo e não partilhavam do mesmo habitus que aqueles que deixaram registros sobre o acontecimento. Essas fontes e a bibliografia que trata da Revolução evidenciam que parte importante da população sul-rio-grandense entrou de forma direta no conflito. As estimativas produzidas indicam que cerca de 10 a 12 mil pessoas perderam a vida no evento (FAY, 1993, p. 35). 
Os revolucionários da época, principalmente os líderes civis e militares dos federalistas, longe de estarem dispostos a uma mudança estrutural profunda, de acordo com o sentido que tradicionalmente é associado à palavra revolução, lutavam por transformações pontuais: a elaboração de uma nova carta constitucional para o Rio Grande do Sul, senão isso, pelo menos a mudança de alguns dos seus dispositivos. De acordo com John Chasteen (2003, p. 60), os envolvidos empregavam a palavra "revolução" com sentido lockeano, isto é, entendiam-na como esforço na perspectiva de restaurar uma ordem política anterior e considerada legítima. ${ }^{3}$

A principal mudança defendida pela maioria dos líderes revoltosos era a substituição do presidencialismo pelo regime parlamentarista, mas, mesmo em relação a tal meta, existiam divergências. Uma delas se referia à forma como o objetivo seria alcançado, pois alguns chefes revolucionários - o Almirante Saldanha da Gama, por exemplo - defendiam que deveria acontecer um plebiscito nacional. A partir dele, a população deveria escolher o melhor regime de governo: uma república presidencialista, parlamentarista ou uma restauração da recém-caída monarquia. Outros propunham que a mudança de regime deveria acontecer juntamente com a vitória da revolução. ${ }^{4}$

"A revolução é um protesto do povo contra seu governo" (DOURADO, 1997, p. 13-14), nestes termos, o Coronel-médico das forças federalistas, Ângelo Dourado, definia o momento que estava vivenciando em 1893-1895. Dourado acompanhou as movimentações das tropas chefiadas por Gumercindo Saraiva, um dos principais generais das tropas revolucionárias. Para o médico, o Rio Grande do Sul, no período, era comparável a um "enfermo". A moléstia era a "revolução" e a causa da doença, o "governo". Definida a doença, a causa e os sintomas, "a luta do médico é com a origem da moléstia, luta da vida com a morte da qual ele é apenas mediador. Se a causa triunfa o doente morre". Era necessário combater a causa da doença e, na Revolução, de acordo com o Coronel, o papel de médico cabia ao povo brasileiro, que, embora "ordeiro na ordem moral", não podia suportar o jugo que lhe foi lançado juntamente com a proclamação da República. Assim, "passada a bestialização", algumas pessoas resolveram levantar armas contra o governo, sendo que o povo, por "falta de educação", precisava de diretores "bons e honestos" para mostrar-lhes o caminho correto.

Ao decompor o pensamento de Dourado, nota-se que a revolução, diferentemente de ser "o protesto do povo contra seu governo", era a mobilização de um povo "calmo", "ordeiro", "bestializado", coordenado por alguns diretores "bons e honestos", dentre os quais, ele próprio, para "salvar a República". Por seu turno, dar conta desse propósito significava "lutar contra todos que se diziam republicanos", ou seja, os castilhistas. Dessa forma, caso a República não pudesse ser salva pela derrubada do governo, Dourado preferia a restauração monárquica: "ainda que nos viesse um Belzebu, com tanto que unificasse o país sem sair da lei" (DOURADO, 1997, p. 13-14). Assim, algumas possibilidades eram cogitadas para salvar o enfermo, mas nenhuma delas deveria redundar em uma mudança social profunda, pelo 
contrário, tudo deveria acontecer, de acordo com Dourado, sem que fosse necessário "sair da lei".

Em linhas gerais, o quadro exposto expressa o pensamento da maioria dos líderes rebeldes e demonstra, igualmente, que a palavra "revolução" adotava o sentido de restauração. Uma consulta geral nos documentos referentes ao acontecimento é suficiente para perceber que o discurso de Dourado é representativo das posições políticas tomadas pelos principais líderes oposicionistas, tais como Silveira Martins e o General Joca Tavares. Alguns dos participantes ativos da contenda, como o Coronel Macedo Fulião, defendiam abertamente o retorno da Monarquia, contudo, o principal líder monarquista - o Almirante Saldanha da Gama - era partidário, como já referi, da realização de um plebiscito nacional para definir o regime de governo mais conveniente ao Brasil.

Sobre o Coronel Macedo Fulião, ${ }^{5}$ que, ao iniciar uma batalha, chamava seus comandados à briga com gritos de "Viva o Imperador", é importante registrar o quanto ele, em relação a alguns de seus companheiros - Silveira Martins, Joca Tavares e Saldanha da Gama -, tinha uma leitura bastante peculiar sobre os significados do que eram a República e a Monarquia. Fulião dava vivas ao Imperador e ao Império porque, segundo Dourado, foi assim que agiu quando, alguns anos antes, havia lutado na Guerra do Paraguai, e dizia: "onde sempre briguei se fala em república e nunca vi nada que prestasse" (DOURADO, 1997, p. 164).

Como é possível perceber, a leitura realizada pelo Coronel Fulião sobre o que era a Monarquia ou a República tomava por suporte o seu passado recente, afinal, não era grande a distância temporal que separava a Federalista da Guerra do Paraguai. Esse fato também é demonstrativo do quanto os indivíduos ou grupos sociais, quando inseridos em momentos de mudança ou crise social, têm a tendência de interpretar as transformações e os processos nos quais estão envolvidos: "com base em padrões de relacionamentos sociais derivados de experiências passadas", as quais, por seu turno, fornecem "modelos de condenação a serem usados contra o presente" (MOORE JR., 1987, p. 206). Situação que se torna ainda mais objetiva nos momentos em que as transformações são acompanhadas de alteração nos padrões de distribuição de riqueza e de prestígio, bem como quando envolvem exploração social. Assim, a experiência de passado, o próprio presente que estavam vivendo e, de certa forma, as perspectivas de futuro daqueles que se envolveram na $\mathrm{Fe}$ deralista são razões importantes e que não podem ser desconsideradas.

A Revolução também tinha um sentido específico para o outro grupo envolvido e que, naquele momento, nas palavras de Dourado, era o "governo". Os líderes castilhistas também viam a Revolução como um mal que devia ser combatido. Contudo, para eles, a causa do problema era, nas palavras de Júlio de Castilhos e de seus correligionários, o desejo de "restauração monárquica", portanto, era obra de alguns "reacionários", "anarquistas de ocasião", "agitadores medíocres" (TEIXEIRA, 1893, p. 181). Para Castilhos, principal liderança legalista e, na época, presidente do estado do Rio Grande do Sul, inicialmente, a Federalista havia assu- 
mido um caráter local, mas tinha por motivo maior alastrar-se pelo restante do país, com o objetivo, portanto, de derrubar o governo Floriano e, juntamente com ele, a República (CASTILHOS, 1894, p. 07-08).

Os argumentos lançados por Júlio de Castilhos têm o sentido de garantir para si o apoio do governo federal. O objetivo de levar a Revolução para fora do Rio Grande do Sul, no entanto, não pode ser negado, pois, em carta enviada pelo Almirante Saldanha da Gama a Silveira Martins, em abril de 1894, o primeiro deixa clara essa vontade. Para ele, sem dar tal passo, a Revolução não encontraria apoio nem recursos fora do território sul-rio-grandense, o que seria muito prejudicial (ABRANCHES, 1914, p. 49). As movimentações das tropas de Gumercindo Saraiva, que saíram do Rio Grande do Sul e foram até o Paraná, deram conta de tentar cumprir a estratégia de Saldanha da Gama. Entretanto, também serviram para justificar os argumentos lançados por Castilhos para garantir o apoio do governo central aos castilhistas.

Outra peculiaridade da Federalista foi a desigualdade de condições reinante entre as duas principais forças envolvidas. Os castilhistas estavam em melhor situação, eram governo, recebiam apoio da União e do exército brasileiro. Já os rebeldes, devido aos parcos recursos que possuíam e às dificuldades de recrutamento, precisaram adotar para si a tática da guerra de guerrilha, método que exigia uma série de conhecimentos específicos, os quais notabilizaram alguns dos seus líderes, como os irmãos Gumercindo e Aparício Saraiva. Dentre tais saberes, destacam-se o conhecimento deta- lhado da geografia para facilitar a mobilidade das tropas, a "recusa em lutar nos termos do inimigo" e, principalmente, "a simpatia e o apoio, ativo e passivo, da população local" (HOBSBAWM, 1982, p. 166). No último caso, as fontes indicam que as tropas federalistas não tiveram muito sucesso, contudo, explica a preocupação expressa por Ângelo Dourado em diversos momentos de seu diário para que, em suas marchas, os soldados do Exército Libertador não cometessem brutalidades com os habitantes dos locais por onde passavam. Ajuda a entender, também, algumas punições recebidas por aqueles que praticavam crimes em nome da Revolução, as quais quase sempre se resumiam em degola ou fuzilamento do infrator.

Uma fonte que traz algumas informações e indícios sobre os fatos que ocorreram durante a Revolução Federalista e que estiveram na base de muitos engajamentos nas forças rebeldes ou legalistas são os relatórios produzidos pelos sacerdotes capuchinhos Bernardin d'Apremont e Bruno Gillonnay (1976, p. 103). Eles atuavam nas colônias italianas existentes na região e também exerciam atividades religiosas entre as populações indígenas. Ao tratar da Revolução Federalista, d'Apremont escreve que, "longe do olhar severo dos chefes", havia espaço para "vinganças particulares de caráter atroz: a brutalidade humana desencadeada mantinha as humildes e pacatas populações num contínuo clima de terror" (1976, p. 103).

No mesmo sentido, em carta enviada à França em 1900, o padre Bruno Gillonnay relata uma missão que realizou nas extremidades das colônias e diz ter entrado em "contato com uma categoria de brasileiros 
toda especial". Tratava-se de pessoas que, devido à Revolução, haviam se "embrenhado nas florestas em busca de refúgio para si e para suas famílias" (1976, p. 100). Gillonnay, descreve tais indivíduos como pessoas que viviam "sem dono, sem culto e sem moral" (1976, p. 100). Da mesma forma, o chefe da Diretoria de Terras e Colonização ${ }^{6}$ (DTC), Carlos Torres Gonçalves, em 1919, escreveu que a Revolução estava na origem do grande número de intrusos ${ }^{7}$ existente nas terras do estado, que ali se estabeleceram fugindo da Federalista (GONÇALVES, 1919, p. 351). Por sua vez, há que se registrar que a atitude de fugir não deve ser compreendida no sentido restrito da palavra, mas como uma daquelas estratégias sociais para as quais chamei atenção no início do artigo, em outros termos, uma das poucas alternativas que as camadas populares têm para lidar com as dificuldades que a situação social que experimentam impõe à sua sobrevivência e reprodução.

Nesse sentido, o ingresso em um batalhão ou em uma tropa, antes de ser considerado como adesão ingênua, deve ser lido como resultado de uma leitura estratégica e cognitiva do mundo social. Augusto Pestana, diretor da Colônia Ijuí, uma das primeiras fundadas na região, em documento enviado à Diretoria de Obras Públicas, datado de 1899, solicita a regularização e o "estabelecimento de grande número de nacionais que prestaram serviços na defesa da República e se estabeleceram na margem direita do Rio Ijuí" (SILVEIRA, 1899, p. 55). O pedido de Pestana indica que a participação na Revolução poderia trazer benefícios aos envolvidos. Observação que ganha signifi- cados profundos quando se considera que, no período, o acesso legal/regularizado à terra era algo bastante difícil de acontecer, especialmente para o grupo social a que Pestana faz referência, os "nacionais".

Embora existam registros de participação de colonos na Revolução, por exemplo, as memórias de João Eickhoff (1996), colono alemão que participou ativamente da guerra civil atuando como médico de um batalhão federalista, é muito difícil definir com exatidão os motivos que levavam os colonos a escolher um dos lados em choque. No caso das áreas de colonização alemã, René Gertz (1993, p. 121) escreve que a procura por definir a posição tomada pelos teuto-brasileiros nesse conflito se demonstra vã. Algumas análises sugerem a existência de uma divisão étnica em que os ítalo-brasileiros, em sua maioria, tendiam a apoiar as forças federalistas devido a pouca atenção que o governo thes destinava (CONSTANTINO, 1993, p. 75-81). Alguns estudiosos indicam a religião como motivo a definir posições, assim, postulam que existia um bom relacionamento entre os teuto-brasileiros protestantes e Silveira Martins. ${ }^{8}$ Situação que foi usada por Júlio de Castilhos e seus partidários para adquirir apoio dos católicos e também para justificar ações em áreas de colonização alemã, principalmente naquelas em que o governo encontrava forte oposição. Isso, contudo, não permite ao estudioso fazer "generalizações no sentido de afirmar que os luteranos tenham sido federalistas e os católicos republicanos, ou vice-versa" (GERTZ, 1993, p. 120). ${ }^{9}$

Uma das atitudes tomadas pelos colonos foi a organização em sociedades de au- 
todefesa, pelas quais tentavam resguardar-se dos ataques de piquetes "governistas e federalistas que incursionavam pelas sedes dos municípios e pelas picadas interioranas" (FLORES, 1983, p. 53). Tais sociedades existiram em diferentes colônias no período. Finda a Revolução, a maioria desapareceu, vindo a renascer em 1923, juntamente com o novo conflito que assolou o Rio Grande do Sul. Segundo Hilda Flores, em 1924, ainda existiam 67 sociedades funcionando no estado. Outro motivo a incentivar os colonos a se organizarem em tais sociedades eram, de acordo com Flores (1983), os constantes ataques de que eram alvos por parte de "grupos assaltantes conhecidos por 'Serranos' ou 'ervateiros'", os quais procediam como "oportunistas que, mesmo não sendo federalistas, assumiam atitude hostil contra o Governo". Para a autora, os "ervateiros" assim agiam como réplica aos intendentes municipais "que faziam recrutamento forçado para suas fileiras" (1983, p. 53).

Além do recrutamento forçado, outro motivo que estava na base das adesões desses grupos aos federalistas era o de que eles eram alvos diretos das expropriações proporcionadas pelo avanço do processo de ocupação das terras da região via fundação de colônias. No caso dos ervateiros, é importante registrar que, a partir das décadas finais do século XIX, muitos ervais da região, que, histórica e juridicamente, eram considerados áreas de servidão pública, tornaram-se propriedade privada. Assim, uma quantidade significativa de pessoas que viviam da coleta e da produção de erva-mate teve o acesso a essas áreas proibido (ZARTH, 2015; GERHARDT, 2013). Dessa maneira, experi- mentaram, de forma concreta, a situação de ter seus direitos transmutados em delitos. Todavia, não ficaram imóveis diante disso. As ações dos ervateiros descritas por Hilda Flores, quando lidas a partir desse ponto de vista, demonstram que o qualitativo de "oportunistas" mais atrapalha do que ajuda a compreender a situação.

Ainda para tratar sobre os impactos da Federalista nas regiões de colonização, o Coronel-médico Ângelo Dourado, ao descrever o deslocamento do batalhão chefiado por Gumercindo Saraiva, que vinha do Paraná para o Rio Grande do Sul, conta que, nas suas movimentações, as tropas também se viam na necessidade de "ir às roças dos pobres lavradores em busca de milho" (DOURADO, 1997, p. 232) para alimento. Em outra passagem de seu diário, Ângelo Dourado narra a necessidade que teve de ocupar a casa de um casal de teuto-brasileiros colonos para se hospedar. $\mathrm{O}$ ajudante a serviço de Dourado, um baiano chamado Emiliano, fez queixas ao médico, pois não havia encontrado nada na casa para fazer almoço e "os diabos dos gringos diziam que nada tinham, até as galinhas que ele [Emiliano] via pela roça lhes diziam não tinham" (1997, p. 137, grifo do autor). Diante da situação, Dourado oferece ao colono uma moeda de dez mil réis, o qual "correu pressuroso após as galinhas para agarrar a mais gorda; apareceram ovos, manteiga fresca, café, açúcar e um esplêndido salame" (1997, p. 137).

Também há registros de existência de tropas organizadas por colonos, como o batalhão Gumercindo Saraiva, formado por polacos de uma colônia do Paraná, onde "a legalidade paranaense cometeu tantas 
opressões que os polacos se levantaram e organizaram um batalhão" (DOURADO, 1997, p. 143). Dourado descreve o $9^{\circ}$ batalhão do Exército Libertador como sendo formado por alemães, espanhóis e índios. Em outro momento, escreve que uma das piores dificuldades que os federalistas experimentaram, no seu retorno ao Rio Grande do Sul, foi enfrentar os "alemães de Pinheiro Machado", que "se defendiam ocultos no mato" (DOURADO, 1997, p. 143).

O General Prestes Guimarães (1987, p. 46), em seu diário, também menciona a existência de um batalhão "brasílico-italiano" que lutava ao lado dos federalistas, formado por mais ou menos cinquenta homens oriundos da colônia Alfredo Chaves. O Capitão-secretário Senna Guasina (1999, p. 94-95) refere-se, em seus diários, ao Sr. Colombo Leoni, "chefe da legião italiana formada no Paraná", o qual, em palestra dada na Sociedade Italiana de Entre-Rios (Argentina), explica que as causas de os colonos italianos entrarem na Revolução se deviam ao fato de "os agentes de Peixoto não respeitarem a propriedade, nem o lar dos europeus que cumprindo deveres de neutralidade recusam tomar parte a seu favor".

Todavia, para os principais líderes governistas, a participação dos colonos era assunto delicado, que não deveria ser tratado de qualquer forma, pois "a produção colonial abastecia a capital e os impostos ali arrecadados foram importantes para custear a guerra" (GERTZ, 1993, p. 116). Nesse sentido, nos relatórios presidenciais enviados à Assembleia dos Representantes, as opiniões, tanto a de Júlio de Castilhos como a de Bor- ges de Medeiros, resumiam-se a destacar que,

[...] durante a época tormentosa da revolução sangrenta em que se angustiou o Rio Grande do Sul por tanto tempo, o Governo só recebeu da população colonial, em regra, o mais ativo e constante apoio (CASTILHOS, 1896, p. 25),

Circunstância esta que, pela descrição realizada, não condiz com o que de fato acontecia na região colonial.

Quanto à participação dos caboclos na Federalista, o diário de Ângelo Dourado também traz informações, principalmente alguns aspectos que caracterizam a sua religiosidade. Dourado descreve a passagem de seu pelotão por uma "pequena aldeia de fabricantes de erva-mate" na região das missões, onde iniciavam os "domínios de um célebre monge que tem percorrido toda a região". Quando as forças federalistas estavam se deslocando em direção a "Santa Maria da Boca do Monte, perto da zona colonial que vai até Estrela", o Coronel-médico relata o contato que manteve com o monge. De acordo com Dourado, ele andava "segurando uma bandeira branca com a figura de uma pomba vermelha no centro", era "moço ainda, figura simpática e ascética". Segundo o relato, o monge participou de alguns combates, sempre empunhando sua bandeira, $\mathrm{e}$ "isto bastou para que os nossos lutassem até vencer, quase sem armas". Na situação, o médico manteve um curto diálogo com o monge, no qual, entre outras coisas, agradeceu a ele por brigar ao seu lado, ao que o monge respondeu que lutava pela justiça, pois "Deus manda que se sofra com os que sofrem" (1997, p. 255-258). ${ }^{10}$ 
Como no caso dos caboclos, a participação de índios e negros na Revolução Federalista é pouco conhecida. Juntamente com os colonos, eles representavam as camadas populares que efetivamente lutaram na guerra civil na região. Para conhecer um pouco melhor tal participação, recorro novamente ao diário de Ângelo Dourado, o qual, certamente, é o relato mais detalhista sobre o conflito. No diário, é possível colher algumas informações, poucas reconheço, mas suficientes para formar uma ideia dessa atuação.

Quando ainda estavam na região de Passo Fundo, Ângelo Dourado narra o contato que ele e seus companheiros tiveram com os "selvícolas", identificando-os como partidários da causa federalista pelo fato de que, anteriormente à sua estada, havia passado Pinheiro Machado e seus comandados, os quais incendiaram as cabanas e as roças dos índios. Dourado também destaca a boa relação que os indígenas mantinham com Prestes Guimarães, General e Chefe dos revolucionários na região, o qual chamavam de "papae Pretin", e também comenta ter encontrado, vivendo com os índios, alguns "soldados desertores, todos negros" (DOURADO, 1997, p. 233-234).

No diário, também constam relatos da contratação de serviços dos indígenas. Quando, nas movimentações das tropas pela região de matas, Dourado informa que os índios eram ajustados para carregar as caixas de munição, pelo que receberiam dois mil réis por cada caixa entregue. Quanto aos negros, as referências aparecem em menor escala e são menos esclarecedoras. ${ }^{11} \mathrm{Na}$ generalidade, das fontes consultadas para este trabalho, há apenas o relato de que viviam em meio aos índios, além de alguns casos esporádicos de negros que, em conversas com o próprio Dourado ou que ele escutou, diziam ter entrado na Revolução para se vingar de algum ato praticado pelos castilhistas.

Outra fonte importante que possibilita discutir a Revolução Federalista a partir do ponto de vista de um soldado raso é o diário produzido por Isidoro Virgínio. De acordo com Carlos Perrone Jobim Júnior (2002, p. 24), que detém os diários, o recruta nasceu em 1877, no município de Rio Grande, era filho de agricultores, entrou para o Exército no fim do século XIX, entre 1890 e 1891, com aproximadamente 13 anos de idade. Jobim Júnior supõe que Isidoro foi recrutado à força. Além de participar da Federalista, fez parte da 4 a Expedição Militar que atacou Canudos, sendo que, após essa experiência, permaneceu "poucos dias no Rio de Janeiro em busca de emprego, mas não obtendo êxito, retornou para Rio Grande" e, "de volta a sua cidade natal, continuou escrevendo sobre o conflito de Canudos" (2002, p. 25).

Um aspecto que chama atenção a respeito de Isidoro é o de que ele era soldado do Exército brasileiro e se identificava com a causa rebelde. O soldado justificava tal paradoxo argumentando que deveria respeitar a instituição na qual estava inscrito, contudo, não deixava de ser crítico ao Exército, tanto em palavras como em atos. Em palavras, Isidoro deixou registrado em seu diário que, naquele momento, $\mathrm{o}$ "militar era um sustentáculo da tirania, um inimigo da liberdade e do povo". Em atos, demonstrou seu descontentamento quando desertou com mais 
dois companheiros para se aliar às forças federalistas. No entanto, desistiu do intento, enquanto seus dois amigos seguiram adiante, em consequência, dias depois, foi preso e reintegrado ao seu batalhão para novamente lutar contra os rebeldes. ${ }^{12}$

Outro fator importante que ajuda a perceber o grau de impacto da Federalista entre as populações que habitavam a região de matas é o de que, mesmo após o término da guerra civil, ela continuou influenciando relações e comportamentos. Antes, destaquei que Carlos Torres Gonçalves, em 1919, indicava a Revolução Federalista como responsável pelo grande número de "intrusos" vivendo na região. No mesmo sentido, em pesquisas realizadas no acervo do Arquivo Público do Estado do Rio Grande do Sul, ${ }^{13}$ encontrei alguns processos-crimes que foram realizados por motivos vinculados à Revolução.

Um desses processos-crimes, datado de 1903 - dez anos após o início da Federalista -, trata de caso ocorrido em Palmeira das Missões, no qual estão envolvidos Américo Lima, Guilherme de Oliveira Matos e Roberto Costa Barreto. Os indivíduos se dirigiram à casa de Jordão Gomes Nogueira para comprar feno, mas não o encontraram em casa, resolvendo ir até a residência de Anacleto Barreto, que ficava perto. Passaram, então, nas imediações da casa de Matias Lourenço, quando "viram uns quantos cavalos encilhados dentro do pátio". Ao passar em frente da casa, cumprimentaram as pessoas que ali estavam e foram respondidos da seguinte forma: "- Agora vocês tomam bala pica-paus bandidos" ${ }^{14}$ Logo após, Américo, Guilherme e Roberto foram atacados "pelos bandidos que saltaram armados para fora do pátio e fizeram descargas de coblaim resultando sair gravemente feridos Guilherme e Roberto". ${ }^{15}$ Os autores do crime, segundo Américo Lima, formavam um grupo de "bandidos perigosos", que

[...] só cuidam em andar de picada em picada prometendo de matar todos os republicanos que entraram na serra do Potreiro Bonito porque dizem que pica-pau lá não tem o que fazer. ${ }^{16}$

Todos os envolvidos no acontecido, em torno de vinte pessoas, definiam-se como lavradores e residiam na mesma localidade, a serra do Potreiro Bonito, $1^{\circ}$ distrito do município de Palmeira. Em linhas gerais, a frase expressa no depoimento de Lima - "pica-pau lá não tem o que fazer" - indica que a força mobilizada e a presença de federalistas na região eram significativas. Da mesma maneira, a briga indica que tal presença não era unívoca. Além disso, a situação como um todo demonstra que se identificar ou ser identificado como chimango ou maragato definia espaços onde quem se identificava ou era identificado poderia ou não atuar e participar.

\section{Considerações finais}

As situações discutidas ao longo deste artigo são descritivas do quanto a inserção das classes populares nas questões políticas que movimentaram a Primeira República no Rio Grande do Sul era resultado de suas leituras próprias do mundo e da situação que viviam. Igualmente, demonstram que a Revolução Federalista adotou uma polissemia de sentidos e significados, que expressa 
a totalidade do evento e demonstra o quão complexas são as relações sociais.

Assim, é possível encontrar exemplos de colonos lutando dos dois lados, de caboclos, negros e índios brigando entre si e de pessoas que, a todo custo, buscavam escapar da contenda. Quanto às elites econômico-políticas, à primeira vista, suas ações parecem mais fáceis de explicar, pois, para elas, o que estava em jogo era o domínio do Estado e, com ele, o controle do poder que tal instituição proporciona, mas, mesmo neste caso, estabelecer motivos fechados é demasiado limitador. ${ }^{17}$

Nas pesquisas realizadas, encontrei vários exemplos da polissemia de sentidos da Revolução Federalista. Um dos que mais chamou atenção refere-se à noção de liberdade, pois um dos principais argumentos utilizados pelos participantes da Federalista era que estavam lutando por ela. Os colonos, quando formavam as mencionadas sociedades de autodefesa, agiam com o argumento de que estavam brigando por sua liberdade de se defender dos ataques sofridos. Quando se alistavam em alguma tropa, diziam que o motivo era porque haviam sido atentados em sua liberdade. Os líderes rebeldes afirmavam que o "governo ditatorial de Castilhos", juntamente com a administração de Floriano Peixoto, roubou a liberdade dos brasileiros e que o sangue derramado nos campos de batalha se transformaria "em germes de liberdade", "em semente, da qual sairá a Árvore da Liberdade que não agasalhará nunca em sua sombra tirano algum" (ABRANCHES, 1914, p. 220).

Os governistas defendiam que quem havia acabado com a liberdade foram os federalistas, pois, "no seio da paz firmemente assegurada, a brilhante evolução da atualidade é a resultante direta da sistemática conciliação da ordem com a liberdade" (MEDEIROS, 1899, p. 03). Para Izidoro Virgínio, a liberdade era "obra divina", portanto, "faz parte do nosso ser". Ao retornar de sua participação em Canudos, pede afastamento do Exército e explica:

[...] [quero] trabalhar para ser livre e senhor de meus narizis. Quero ser, senhor do meu fucinho, ser cidadão e não escravo de outros homens (JOBIM JUNIOR, 2002, p. 65-69).

Quando Ângelo Dourado pergunta ao monge a razão de, juntamente com seus companheiros, estar lutando, ele responde que o motivo era a justiça e porque Deus mandava que se sofresse com os que sofrem.

Como busquei demonstrar ao longo do artigo, os diferentes significados presentes nas fontes e nos relatos produzidos sobre a Revolução Federalista são expressão da condição social, isto é, dos diferentes lugares ocupados no mundo social, por parte daqueles que produziam as explicações. Nesse sentido, um camponês da região de matas do Rio Grande do Sul (agregado, peão, pequeno posseiro, colono, jornaleiro, etc.), ao entrar em algum batalhão, não tinha, necessariamente, como perspectiva o Estado, o regime de governo ou algo do gênero. Algumas vezes, a vingança em relação a algum ato ou a alguma violência sofrida era o motivo, outras vezes, era porque, numa situação de conflito, não tomar partido significa estar exposto a arbitrariedades que podem ter origem em todos os lados envolvidos e, além disso, não ter a proteção de um grupo a quem se possa recorrer. Da mesma forma, participar também 
poderia ser uma forma de garantir, estrategicamente, ainda que em um futuro incerto, limites mínimos de sobrevivência, uma aposta: a possibilidade de acesso à terra, como exemplifica o caso dos "nacionais que prestaram serviço na defesa da República", mencionado pelo diretor da Colônia Ijuí.

Desse modo, um dos principais objetivos foi destacar a atuação dessas pessoas, as quais, em alguns estudos sobre a Revolução Federalista, são retratadas como "uma massa que foi coagida a lutar por interesses completamente alheios" (PESAVENTO, 1983, p. 91). A intenção era demonstrar que esse tipo de explicação não dá conta das vicissitudes e da complexidade características das relações sociais. Argumentar que as pessoas estavam "acostumadas a obedecer, a viver na dependência de coronéis, sem opção de vida, sem terra, sem recursos e brutalizados" (PESAVENTO, 1983, p. 91) é fazer uma afirmação que não permite compreender os motivos sociais e estratégicos de tais comportamentos. Em outros termos, torna-os naturais, como que inatos, absolutiza-os ou trata-os como expressão de uma ignorância inexplicável. Enfim, não leva em consideração seu conteúdo social, cognitivo e político.

\section{Abstract}

In this article, based on the analysis of sources that were produced by people who have participated in the Federalist Revolution (1893-1895), either as foot soldiers or as military and political leaders, the opposition of these documents with the literature that tried to study the event, I seek to discuss the different ways that the Federalist Revolution adopted in the region of Rio Grande do Sul forests - municipalities of Cruz Alta, Palmeira das Missões, Passo Fundo, and Santo Ângelo. It is interesting to show how the various meanings expressed the social condition and situations, experienced then by rural people living in the region.

Keywords: Monarchy. Republic. Revolution. Settlement.

\section{Resumen}

En este artículo, las fuentes de análisis han sido producidas por personas que han participado en la Revolución Federalista (1893-1895), como soldados o como lideranzas militares y politicas, el contraste de estos documentos con la literatura que trataba de estudiar el caso, busqué discutir las diferentes direcciones que la Revolucion Federalista logro en la región de las matas de Rio Grande do Sul - municipios de Cruz Alta, Palmeira das Missões, Passo Fundo y Santo Angelo. Nos interesa mostrar lo cuanto los diversos significados expresaron las condiciones sociales y las situaciones entonces experimentadas por las comunidades rurales que habitaban la región.

Palabras clave: Asentamiento. Monarquía. República. Revolución.

\section{Notas}

1 Para uma definição mais precisa do termo, ver: Marcio Antônio Both da Silva (2014).

2 Sobre essa questão, especificamente para o caso do município de Palmeira das Missões, ver: Lurdes Grolli Ardenghi (2003).

3 Para conhecer as influências teóricas e as visões políticas que eram partilhadas, discutidas e ex- 
pressas pelos grupos envolvidos na Revolução Federalista, ver: Marcus Vinicius da Costa (2006).

4 Joseph Love (1975, p. 65-66) destaca que, devido a estas circunstâncias, os dois principais chefes do movimento, Joca Tavares e Silveira Martins decidiram deixar seus objetivos últimos sem definição.

5 John Chasteen (2003, p. 84) caracteriza Manuel Rodrigues de Macedo (Macedo Fulião) como um homem que gozava de privilégios devido à hierarquia militar, pois, além de não ser grande proprietário de terras, era mulato, fatos que lhe "garantiam ficar à vontade em meio aos soldados rasos", dos quais se diferenciava unicamente devido ao seu posto militar.

6 A DTC era a agência de Estado incumbida de lidar com as questões relativas à colonização e gerenciava o processo de ocupação das terras na região.

7 Sobre a questão da intrusão e seus significados em relação aos conflitos agrários que marcaram a região no período, ver: Marcio Antônio Both da Silva (2011).

8 O apoio dos teuto-brasileiros protestantes a Silveira Martins resulta de sua atuação durante o período imperial, no sentido de o Estado reconhecer e oportunizar espaços de culto para as religiões protestantes.

9 Para aprofundar as discussões sobre o envolvimento das diferentes religiões na Federalista, ver: Helga I. Landgraf Piccolo (1995).

10 O diário de Ângelo Dourado ilumina uma questão que ainda não recebeu atenção proporcional à sua importância, ou seja, o papel da religiosidade popular, principalmente do messianismo entre os grupos de lavradores pobres. Alguns estudos recentes têm pautado essa questão, principalmente chamando atenção para a relação dos $\mathrm{Fe}$ deralistas com movimentos - o Contestado, por exemplo - que alcançaram grande proporção no sul do Brasil. Nesse sentido, ver: Paulo Pinheiro Machado (2004).

11 Talvez o negro que participou da Federalista a quem mais se faça referência seja o Tenente-coronel Adão Latorre. Ele era filho de escravos e homem de confiança da família Tavares, uma das principais envolvidas na Revolução. Latorre "era um negro pobre, que cuidava das estâncias dos Tavares, dividindo seu tempo entre as lides de campo e as tarefas militares" (CAVALARI, 2001, p. 97). As constantes referências a Latorre devem-se à sua participação no combate do Rio Negro, ocorrido na região de Bagé em novembro de 1894. Do confronto, saíram vencedores os federalistas, e foram presos cerca de 300 soldados das tropas governistas, os quais foram todos degolados, e o comando das execuções ficou sob responsabilidade de Latorre. Sobre Latorre e também sobre a "vingança" executada pelos castilhistas no combate do Boi Preto, ocorrido na região de Cruz Alta, no qual foram degolados cerca de 370 maragatos, ver: Rossano Viero Cavalari (2001).

12 As citações são dos diários de Isidoro Virgínio e podem ser consultadas na dissertação de mestrado de Carlos Perrone Jobim Júnior (2002, p. 23, 30). Destaco que não tive acesso a tais diários em função de que, no momento em que fiz a pesquisa, eles estavam sob a guarda de Jobim. A esperança é a de que ele tenha doado esses documentos a alguma instituição de pesquisa, a fim de que tal acesso seja ampliado.

13 APERGS. Processo Crime n ${ }^{\circ}$ 198. Cartório Civil Crime. Município de Palmeira das Missões, 1903. Maço 10.

14 Os termos "pica-paus" e "chimangos" eram utilizados para fazer referência aos integrantes das forças governistas. Por sua vez, os federalistas eram identificados com o adjetivo "maragatos". Todas essas palavras, a princípio, carregavam um conteúdo pejorativo, mas, com o tempo, passaram a ser símbolos de identidade e orgulho. Para conhecer a origem e o significado de tais termos, ver: Sandra Jatahy Pesavento (1983).

15 APERGS. Processo Crime n ${ }^{\circ}$ 198. Cartório Civil Crime. Município de Palmeira das Missões, 1903. Maço 10.

16 APERGS. Processo Crime n ${ }^{\circ}$ 198. Cartório Civil Crime. Município de Palmeira das Missões, 1903. Maço 10.

17 Para conhecer as fissuras que caracterizavam as classes dominantes da Primeira República, ver: Sônia Regina Mendonça (1997) e Renato Perissinotto (1994).

\section{Referências}

ABRANCHES, João Dunshee. A revolta da armada e a revolução riograndense: correspondência entre Saldanha da Gama e Silveira Martins. Rio de Janeiro: M. Abranches Editor, 1914.

ARDENGHI, Lurdes Grolli. Caboclos, ervateiros e coronéis. Passo Fundo: UPF, 2003.

BOURDIEU, Pierre. A economia das trocas simbólicas. São Paulo: Perspectiva, 1982. 
CASTILHOS, Júlio Prates de. Mensagem enviada à Assembleia dos Representantes do Estado do Rio Grande do Sul pelo presidente Júlio Prates de Castilhos em 20 de Setembro de 1894. Porto Alegre: Tipografia de Cesar Renhardt, 1894.

. Mensagem enviada à Assembleia dos Representantes do Rio Grande do Sul pelo Presidente Júlio Prates de Castilhos, 20 de setembro de 1896. Porto Alegre: Tipografia de Cesar Renhardt, 1896.

CAVALARI, Rossano Viero. Cruz Alta na Revolução de 1893: o ninho de pica-paus. Porto Alegre: Martins Livreiro, 2001.

CHASTEEN, John. Fronteira rebelde. Porto Alegre: Movimento, 2003.

CONSTANTINO, Núncia Santaro de. Italianos no processo revolucionário. In: FLORES, Moacyr (Org.). 1893-1895: a revolução dos maragatos. Porto Alegre: EDIPUCRS, 1993. p. 75-81.

COSTA, Marcus Vinicius da. A Revolução Federalista (1893-1895): o contexto platino, as redes, os discursos e os projetos políticos liberal-federalistas. 2006. Dissertação (Mestrado em História) - Universidade Federal de Santa Maria, Santa Maria, 2006.

D'APREMONT, Bernardin; GILLONAY, Bruno de. Comunidades indígenas, brasileiras, polonesas e italianas no Rio Grande do Sul (1896-1915). Porto Alegre: EST; Caxias do Sul: UCS, 1976.

DOURADO, Ângelo. Voluntários do martírio: narrativa da revolução de 1893. Porto Alegre: Martins Livreiro, 1997.

EICKHOFF, João. O doutor maragato. Porto Alegre: Editora Ufrgs, 1996.

ELIAS, Norbert. A sociedade dos indivíduos. Rio de Janeiro: Jorge Zahar, 1994.

FAY, Cláudia Musa. O legado da revolução de 1893. In: FLORES, Moacyr (Org.). 1893-1895: a revolução dos maragatos. Porto Alegre: EDIPUCRS, 1993. p. 35-40.
FÉLIX, Loiva Otero. Coronelismo, borgismo e cooptação política. Porto Alegre: Editora Ufrgs, 1996.

FLORES, Hilda Agnes Hübner. Santa Clara na Revolução Federalista de 1893. In: SEMINÁRIO FONTES PARA A HISTÓRIA DA REVOLUÇÃO DE 1893, 1983, Bagé. Anais... Bagé: URCAMP, 1983. p. 53-56.

FRANCO, Sérgio da Costa. Razão de ser. In: SCHIERHOLT, José Alfredo. Revolução Federalista no Vale do Taquari. Lajeado: Grupo Cartel, 1989. p. 10-11.

GERHARDT, Marcos. História ambiental da erva-mate. 2013. Tese (Doutorado em História) - Universidade Federal de Florianópolis, Florianópolis, 2013.

GERTZ, René E. Aspectos da Revolução Federalista nas regiões de colonização alemã. In: ALVES, Francisco das Neves; TORRES, Luiz Henrique (Org.). Pensar a Revolução Federalista. Rio Grande: Editora Furg, 1993. p. 115-121.

GONÇALVES, Carlos Torres. Relatório da Diretoria de Terras e Colonização. In: PINTO, Ildefonso Soares. Relatório apresentado ao Dr. Antônio Augusto Borges de Medeiros presidente do Estado do Rio Grande do Sul pelo Dr. Ildefonso Soares Pinto Secretário de Estado dos Negócios das Obras Públicas em 27 de agosto de 1919. Porto Alegre: Oficinas Gráficas de A Federação, 1919. p. 347-452.

GUASINA, Luiz de Senna. Diários da Revolução Federalista. Porto Alegre: Arquivo Histórico do Rio Grande do Sul/EST Edições, 1999.

GUIMARÃES, Antônio Ferreira Prestes. A Revolução Federalista em cima da serra (1892-1895). Porto Alegre: Martins Livreiro, 1987.

HOBSBAWM, Eric. J. Revolucionários. Rio de Janeiro: Paz e Terra, 1982.

JOBIM JÚNIOR, Carlos Perrone. "A vida mal vivida". Diário de um maragunço. 2002. Dissertação (Mestrado em História) - Universidade Federal do Rio Grande do Sul, Porto Alegre, 2002. 
LOVE, Joseph. O regionalismo gaúcho e as origens da revolução de 1930. São Paulo: Perspectiva, 1975.

MACHADO, Paulo Pinheiro. Lideranças do Contestado. Campinas: Unicamp, 2004.

MEDEIROS, Antônio Augusto Borges. Mensagem enviada à Assembleia dos Representantes, pelo Presidente do Estado do Rio Grande do Sul, Antônio Augustos Borges de Medeiros em 20 de Setembro de 1899. Porto Alegre: Oficinas Gráficas de A Federação, 1899.

MENDONÇA, Sonia Regina de. O ruralismo brasileiro (1888-1931). São Paulo: Hucitec, 1997.

MOORE JR., Barrington. Injustiça: as bases sociais da obediência e da revolta. São Paulo: Brasiliense, 1987.

PERISSINOTTO, Renato M. Classes dominantes e hegemonia na República Velha. Campinas: Editora Unicamp, 1994.

PESAVENTO, Sandra Jatahy. A Revolução Federalista. São Paulo: Brasiliense, 1983.

PICCOLO, Helga I. Landgraf. Religião e participação política. In: RAMBO, Arthur Blásio; FÉLIX, Loiva Otero (Org.). A Revolução Federalista e os teuto-brasileiros. São Leopoldo: Unisinos; Porto Alegre: Ufrgs, 1995. p. 57-68.

. Fontes para o estudo da Revolução Federalista de 1893. In: SEMINÁRIO FONTES PARA A HISTÓRIA DA REVOLUÇÃO DE 1893, 1983, Bagé. Anais... Bagé: URCAMP, 1983. p. $40-50$.

SILVA, Marcio Antônio Both da. Caboclos. História Unisinos, São Leopoldo, v. 18, n. 2, p. 338-351, maio/ago. 2014.

. Babel do novo mundo. Niterói: EDUFF; Guarapuava: Unicentro, 2011.

SILVEIRA, Francisco de Ávila. Diretoria de Obras Públicas, $2^{\mathrm{a}}$ secção terras e colonização. In: PAROBÉ, João José Pereira. Relatório dos negócios de Obras Públicas apresentado ao Exm. Sr. Desembargador Antônio Augusto Borges de Medeiros presidente do Estado do Rio Grande do Sul pelo secretário de Estado João José Pereira Parobé em 31 de julho de 1899. Porto Alegre: Oficinas Gráficas de A Federação, 1899. p. 41-64.

TEIXEIRA, Múcio Scoevola Lopes. A revolução do Rio Grande do Sul. Porto Alegre: Tipografia do Jornal do Comércio, 1893.

VILLELA, Jorge Luiz Mattar. O povo em armas: violência e política no sertão de Pernambuco. Rio de Janeiro: Relume-Dumará, 2004.

WASSERMAN, Cláudia. O Rio Grande do Sul e as elites gaúchas na Primeira República: guerra civil e crise no bloco do poder. In: GRIJÓ, Luiz Alberto et al. (Org.). Capítulos de história do Rio grande do Sul. Porto Alegre: Editora Ufrgs, 2004. p. 273-289.

ZARTH, Paulo Afonso. Terras de uso comum nos ervais do Rio Grande do Sul. In: SILVA, Marcio Antônio Both; KOLING, Paulo José. Terra e poder: abordagens e perspectivas. Porto Alegre: FCM, 2015. p. 56-72. 